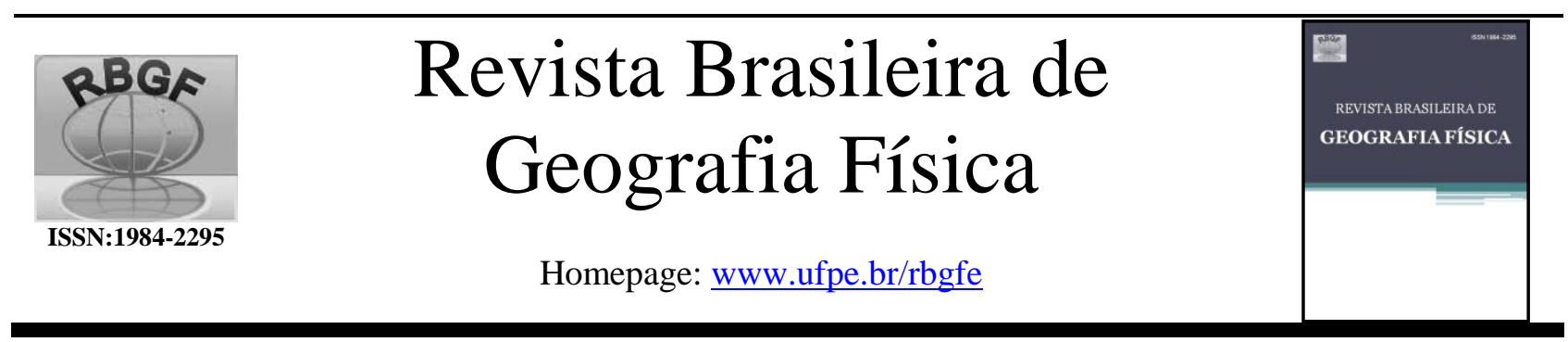

\title{
Atributos geomorfométricos e cobertura e uso da terra: análise na bacia hidrográfica do arroio Carijinho - Rio Grande do Sul
}

\author{
André Ricardo Furlan, Universidade Federal de Santa Maria. E-mail: andre.ricardofurlan@gmail.com \\ Daniélli Flores Dias. Universidade Federal de Santa Maria. E-mail: daniellidias08@gmail.com \\ Romario Trentin. Universidade Federal de Santa Maria. E-mail: romario.trentin@ gmail.com \\ Luís Eduardo de Souza Robaina. Universidade Federal de Santa Maria. E-mail: lesrobaina@ yahoo.com.br
}

Artigo recebido em 27/10/2017 e aceite em 20/06/2018

\begin{abstract}
R E S U M O
A pesquisa tem como objetivo estabelecer a relação entre o padrão de formas do terreno, representado pelos parâmetros geomorfométricos e as diferentes classes de cobertura e uso da terra. A área de estudo corresponde a Bacia Hidrográfica do Arroio Carijinho, que está localizada na porção central do Estado do Rio Grande do Sul, abrangendo uma área referente a $162,71 \mathrm{~km}^{2}$. A pesquisa se justifica pela não existência de materiais e trabalhos acadêmicos que auxiliam na elaboração de políticas públicas para os municípios. Além disso, o canal principal do Arroio Carijinho, possui a barragem da Companhia Riograndense de Saneamento (CORSAN) que auxilia no abastecimento de água potável. Os dados topográficos de altitude, declividade e plano de curvatura foram obtidos a partir do SRTM (90m) e trabalhados em uma árvore de decisão. $\mathrm{O}$ uso e a cobertura da terra na bacia hidrográfica utilizou-se uma imagem do satélite Sentinel - 2B de 02/07/2017 com resolução espacial de 10 metros. A análise dos parâmetros topográficos definidos, gerou oito unidades geomorfométricas distintas. O cruzamento entre a geomorfometria e as classes de cobertura e uso da terra demonstram a atuação do homem, associado as relações sociais envolvidas sobre as formas de relevo. Evidencia-se a importância do estudo do relevo no planejamento ambiental aliado ao ordenamento territorial, tendo como base a definição de locais apropriados para os diferentes usos.

Palavras-Chave: Geomorfometria; Bacia Hidrográfica; Planejamento.
\end{abstract}

\section{Geomorphometric attributes and coverage and use of the land: analysis in the river basin of arroio Carijinho - Rio Grande do Sul}

\section{A B S T R A C T}

The research aims to establish the relationship between the pattern of the landforms, represented by geomorphometric parameters, and the different classes of coverage and use of the land. The study area corresponds Hydrographic Basin to the Arroio Carijinho, which is located in the central portion of the Rio Grande do Sul, with area of $162.71 \mathrm{~km}^{2}$. The research is justified by the lack of materials and academic works that help in the elaboration of public policies for the municipalities. In addition, the main channel of Arroio Carijinho, has a dam of Companhia Riograndense de Saneamento (CORSAN) that assists in the supply of drinking water. The topographic data of altitude, slope and curvature plane were obtained from the SRTM $(90 \mathrm{~m})$ and worked on a decision tree. The use and cover of the land in the hydrographic basin was used an image of the satellite Sentinel - 2B of 02/07/2017 with spatial resolution of 10 meters. The analysis of the defined topographic parameters generated eight different geomorphometric units. The cross between the geomorphometry and the classes of cover and use of the land demonstrate the performance of the man, associated with the social relations involved on the landforms. It is evident the importance of the study of the relief in the environmental planning allied to the territorial planning, based on the definition of appropriate places for the different uses.

Keywords: Geomorphometry; Hidrographic basin; Planning 


\section{Introdução}

Os estudos de cunho geomorfológico na atualidade possuem relações diretas entre a manipulação de dados topográficos, procurando apresentar o modelo atual da superfície terrestre. Para a compreensão dos processos atuantes emprega-se o papel do sensoriamento remoto, que se vincula a manipulação e tratamento de imagens de satélite, com resoluções espaciais e temporais. A partir do cruzamento entre as variáveis topográficas resultantes da morfometria aliado as características da cobertura e uso da terra, apresenta-se uma síntese na compreensão das dinâmicas e processos atuais. Essa compreensão torna-se possível de ser aplicada e melhor interpretada, quando se leva em consideração a escala de análise da bacia hidrográfica.

A partir do final da década de 1960, a bacia hidrográfica tem-se apresentado como uma unidade espacial privilegiada para análises em Geografia Física. Caracteriza-se por ser uma área composta por uma porção de terras, que possui drenagem até um rio principal ou um afluente. A partir dessa unidade é possível conhecer e avaliar os seus diversos componentes e os processos de intervenção que nela ocorrem (Guerra; Guerra, 1997; Botelho; Silva, 2010; Botelho, 2011).

Concordando com isso, é importante destacar que a bacia hidrográfica possui relevância para a análise e compreensão de áreas degradadas. Segundo Araújo et al. (2010), não se pode compreender os processos de alteração na dinâmica da bacia hidrográfica apenas próximo ao canal fluvial, pois todos os sedimentos $\mathrm{e}$ alterações que os geram são transportados dos interflúvios até o talvegue. Considerada para o planejamento ambiental, ela possibilita "avaliar de forma integrada as ações humanas sobre $\mathrm{o}$ ambiente e seus desdobramentos sobre o equilíbrio hidrológico, presente no sistema representado pela bacia de drenagem" (Botelho e Silva, 2010, p. 155).

No decorrer das últimas décadas, a análise de bacia hidrográfica vem empregando estudos que procuram identificar as formas de relevo vinculados a essa unidade de análise. Diante disso, considera-se que o relevo se refere as saliências e reentrâncias da superfície terrestre, que podem ser descritas e caracterizadas em diferentes escalas.

Em relação aos estudos que compreendem a parametrização ou a morfometria do relevo, identifica-se a representação quantitativa das características morfológicas a partir de métodos automatizados em ambiente de Sistema de Informação Geográfica (SIG), obtendo o mapeamento desejado (Wood, 1996; Florenzano, 2008; Valeriano, 2008).
Nesse sentido, observa-se a preocupação de diversos autores, que procuram compreender a aplicação de modelos digitais na análise do relevo. Dessa forma, parâmetros obtidos dos Modelos Digitais do Terreno (MDTs) tratam de mensurações quantitativas das formas de relevo, onde percebe-se diversas designações.

Para Moore et al. (1991, 1993); Wilson; Gallant (2000); Chagas (2006); Silveira et al. $(2012,2013)$ a terminologia utilizada é de atributos topográficos. Speight (1968) aborda em seu trabalho questões referentes aos parâmetros das formas do relevo, Valeriano (2003), Valeriano e Carvalho Júnior (2003) definem o termo variáveis topográficas, Shary et al. (2002) e Valeriano (2005) classificam a nomenclatura de variáveis morfométricas, Muñoz (2009) e Bispo et al. (2009) classificam em seus estudos como análise das variáveis geomorfométricas, Martinoni (2002) utiliza o termo informações do terreno, Pennock (2003), Vasconcelos et al. (2012) constroem o termo de atributos do terreno, Schmidt e Dikau (1999) tratam a temática como atributos geomorfométricos, por fim, Ippoliti et al. (2005) e Sirtoli et al. (2008) apresentam a perspectiva de atributos do relevo.

Independente das terminologias, os estudos quantitativos do relevo vêm sendo desenvolvidos desde Speight (1968) no final da década de 1960. Assim tem-se que as variações topográficas podem ser parametrizadas a partir de diversas variáveis, dentre elas, destacam-se: altitude, declividade e plano de curvatura, que são responsáveis pela compartimentação geomorfométrica de uma determinada área, sendo que é a partir dos Modelos Digitais de Elevação (MDE) como os gerados através das cartas topográficas e das imagens de RADAR Shuttle Radar Topography Mission (SRTM) é que se podem obter e gerar essas informações.

Por sua vez, a cobertura e uso da terra está ligado intrinsicamente a diversos estudo de cunho geográfico e ambiental, tendo que este diagnóstico preciso auxilia no ordenamento territorial. É possível identificar a partir das classes de cobertura e uso da terra, quais são as áreas que necessitam maiores atenção em relação aos impactos possíveis. Vale lembrar que qualquer alteração na cobertura vegetal influencia nas mudanças e no comportamento do balanço hidrológico. Essas transformações induz a redução dos estoques de água que estão contidas nos aquíferos subterrâneo (Coelho-Neto; Avelar, 2007, p.67).

\section{Área de Estudo}

A Bacia Hidrográfica do Arroio Carijinho 
(Figura 1) está localizada na porção central do Estado do Rio Grande do Sul, abrange área referente a $162,71 \mathrm{~km}^{2}$, associada ao Comitê de Bacia Hidrográfica (CBH) do Alto Jacuí (CBH-RS, 2017). Os municípios contemplados pela BHAC são Passa Sete, Lagoa Bonita, Sobradinho, Ibarama e Arroio do Tigre.
Geomorfologicamente, a bacia está incluída no Domínio Morfoestrutural dos Depósitos Sedimentares, na Região Geomorfológica do Planalto das Araucárias, subdividido nas Unidades Geomorfológicas Planalto dos Campos Gerais (alto e médio curso da bacia hidrográfica) e Serra Geral (baixo curso da bacia hidrográfica) (IBGE, 2003).

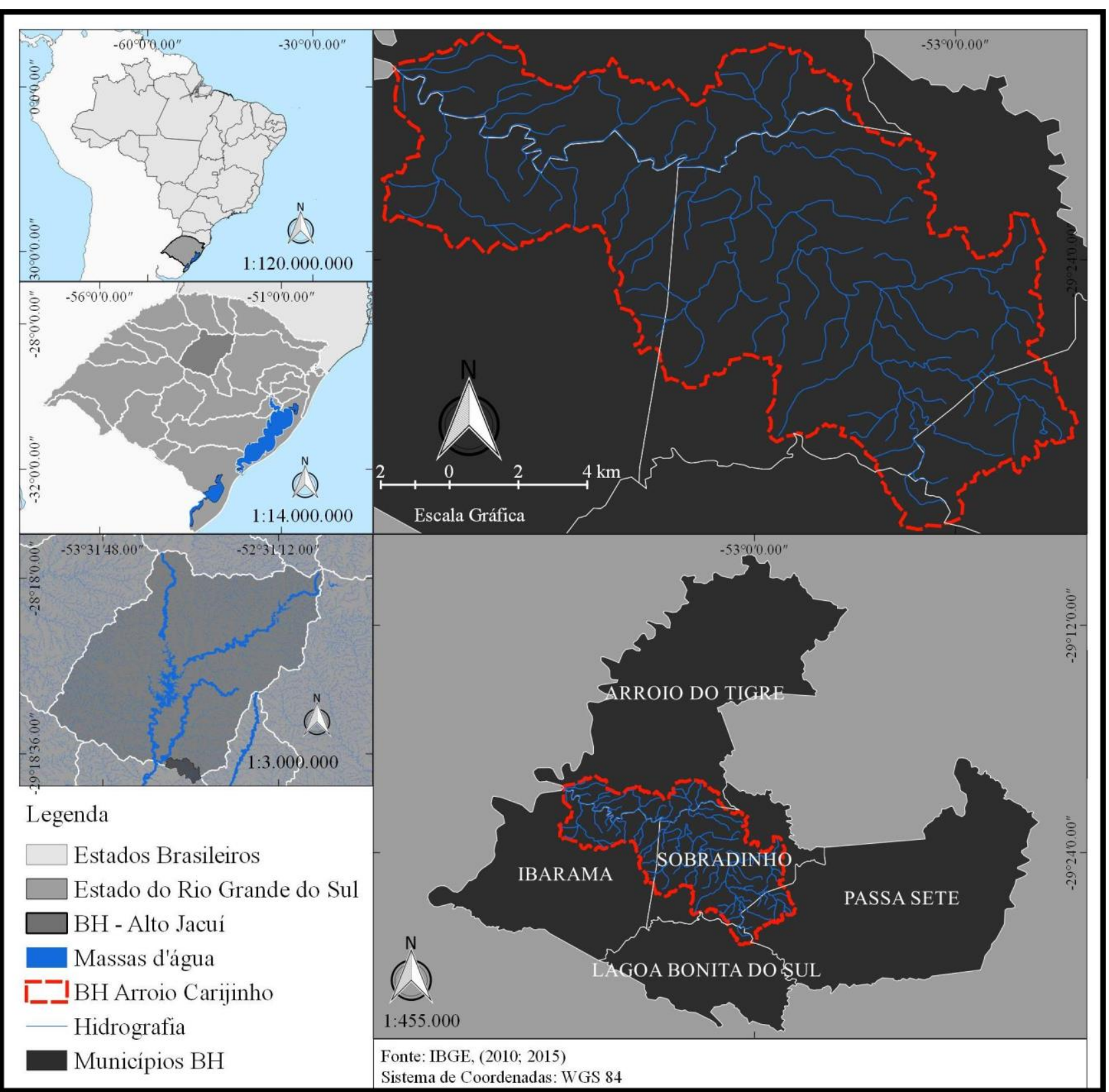

Figura 1 - Mapa de localização da área de estudo.

A pesquisa se justifica pela não existência de materiais e trabalhos acadêmicos que auxiliam na elaboração de políticas públicas para os municípios e para a área da bacia hidrográfica.

Elenca-se que a área urbana de Sobradinho está sobreposta próximo ao canal principal do Arroio Carijinho, e possui barragem da Companhia Riograndense de Saneamento (CORSAN) que auxilia no abastecimento de água potável para o município. Dessa maneira o estudo vem colaborar com levantamento de dados morfométricos, e também identificar quais coberturas e usos da terra vem sendo efetivados no contexto da bacia hidrográfica e das Unidades Geomorfométricas.

Sendo assim, esse artigo tem como objetivo estabelecer a relação entre o padrão de 
formas do terreno, representado pelos parâmetros geomorfométricos com as diferentes classes de cobertura e uso da terra, que auxilia nas estratégias de planejamento ambiental e ordenamento territorial.

\section{Material e métodos}

A etapa inicial ocorreu a partir da delimitação da área de análise (bacia hidrográfica), onde Guerra e Guerra (1997), Botelho e Silva (2010) e Botelho (2011) auxiliaram na compreensão dessa escala de análise, assim como no enfoque de Araújo, Almeida e Guerra (2007) em relação da configuração do relevo e a bacia hidrográfica. Wood (1996), Florenzano (2008) e Valeriano (2008) auxiliaram na compreensão das analises morfométricas e na parametrização do relevo; e a partir dos trabalhos de Guadagnin e Trentin, (2014); Guadagnin et al., (2015); Trentin et al, (2015), Dias et al., (2016); Trentin e Robaina, (2016) e Prina e Trentin (2016) definiu-se a combinação da árvore de decisão expressa na legenda das Figuras 2 e 3.

$$
\mathrm{Na} \text { definição das unidades }
$$

geomorfométricas foram utilizados alguns parâmetros topográficos. A altitude foi o primeiro parâmetro a ser analisado, pois diferentes altitudes podem gerar variações nas condições de temperatura e precipitação que alteram o desenvolvimento de processos superficiais. Além disso, indicam as áreas com presença de cabeceiras de drenagem e as que marcam o nível da base na bacia, indicando processos erosivos e de sedimentação. O parâmetro altitude foi definido a partir da média da amplitude altimétrica, dividindo a área de estudo em duas classes: < 414 metros e $>414$ metros.

O segundo parâmetro de análise foi a declividade, que representa a inclinação das vertentes condicionando diretamente na relação entre escoamento e infiltração nas encostas. $\mathrm{O}$ limite definido foi de $15 \%$, onde tem-se que abaixo de $15 \%$ é identificado um relevo colinoso e de morros com vertentes suavizadas; já acima de $15 \%$ são encontrados relevos fortemente ondulados à escarpados. Essa declividade também consta de limite para o processo de mecanização agrícola ou em áreas urbanas a necessidade de cortes e aterros em obras de engenharia (IPT, 1981).

O terceiro parâmetro utilizado é o plano de curvatura, que é indispensável para o entendimento dos processos superficiais que atuam nas formas de relevo (Chagas, 2006; Sirtoli et al., 2008), e referese ao plano convergente e divergente dos fluxos de matéria sobre o terreno, quando esse é analisado em uma projeção horizontal (Valeriano e Carvalho Junior, 2003).

A partir da aquisição dos dados topográficos do SRTM 90 metros, foram realizados a transformação da projeção WGS 84 para SIRGAS 2000/UTM 22S no software ArcGIS ${ }^{\circledR}$ 10.4. O próximo procedimento constou na aplicação da remoção dos pixels espúrios das imagens do radar seguindo a sequência ArcToolbox $\rightarrow$ Spatial Analyst Tools $\rightarrow$ Hydrology $\rightarrow$ Fill realizado no ArcGIS ${ }^{\circledR}$.

Para gerar a declividade utilizou-se a sequência ArcToolbox $\rightarrow$ Spatial Analyst Tools $\rightarrow$ Surface $\rightarrow$ Slope no software ArcGIS ${ }^{\circledR}$. O terceiro parâmetro utilizado é o plano de curvatura, definido por Convergente (negativa) e Divergente (positiva). O plano de curvatura é gerado nas ferramentas ArcToolbox $\rightarrow$ Spatial Analyst Tools $\rightarrow$ Surface $\rightarrow$ Curvature no ArcGIS ${ }^{\circledR}$.

Para definir o padrão dos parâmetros é necessário realizar a reclassificação dos dados através dos procedimentos: ArcToolbox $\rightarrow$ Spatial Analyst Tools $\rightarrow$ Reclass $\rightarrow$ Reclassify no ArcGIS $^{\circledR}$. Após esse procedimento, realiza-se o cruzamento propriamente dito, por meio das seguintes etapas: Arc Toolbox $\rightarrow$ Spatial Analyst Tools $\rightarrow$ Local $\rightarrow$ Combine no ArcGIS®. Após a combinação dos parâmetros se faz necessário realizar a conversão de raster para polígono ArcToolbox $\rightarrow$ Conversion Tools $\rightarrow$ From Raster $\rightarrow$ Raster to Polygon no $\operatorname{ArcGIS}^{\circledR}$ para a quantificação das classes geomorfométricas.

Em contrapartida, para gerar o uso e a cobertura da terra na bacia hidrográfica utilizou-se uma imagem do satélite Sentinel $-2 \mathrm{~B}$ de 02/07/2017 com resolução espacial de 10 metros, sendo utilizadas as bandas B08, que registra o infravermelho próximo; B04 que representa o vermelho; B03 que apresenta o verde; portanto realizando uma composição identificada como falsa cor.

O processo de composição e classificação da imagem realizou-se no software $\mathrm{ENVI}^{\circledR}$ onde foi aplicado o método de classificação supervisionado por máxima verossimilhança (MAXVER). Para verificar a expressividade de cada amostra foi aplicada a matriz de confusão pelo Coeficiente de Kappa, oferecendo índice superior a 0.88. Em relação ao método MAXVER, Fitz (2008, p.134) enfatiza que essa aplicação "certamente é, hoje, o mais utilizado dentre os classificadores supervisionados".

A partir da classificação foram delimitadas classes de cobertura e uso da terra de acordo com Manual Técnico de Uso da Terra (IBGE, 2013). A partir do nível I, foi possível verificar cinco classes, 
as Áreas Antrópicas não Agrícolas; Áreas Antrópicas Agrícolas; Áreas de Vegetação Natural; Águas e Outras Áreas.

Para o Nível II foram identificadas sete classes: Área Urbana, Cultura Temporária, Pastagem, Silvicultura, Florestal, Água e Área Descoberta.

Desta forma, as Áreas Antrópicas não Agrícolas são compreendidas pela Área Urbana. Em relação a esse tipo de usos, verifica-se diversos problemas de contaminação por produtos tóxicos (Silva, 2011), também condicionam a impermeabilidade reduzindo o processo de infiltração, fazendo com que o escoamento da água seja mais rápido e com maior intensidade, contribuindo na carga de sedimentos. Outro contribuinte para degradação dessas áreas consiste no lançamento de águas servidas diretamente nos canais fluviais (Botelho, 2011).

As Áreas Antrópicas Agrícolas, contemplam as classes de Cultura Temporária em que foram identificadas lavouras de soja, milho, trigo, feijão e tabaco. As classes de Pastagem referem-se as áreas campestres utilizadas para criação de gado.

As áreas com Silvicultura, correspondem ao plantio de eucalipto, devido à grande demanda de sua utilização para secagem do tabaco em estufa. $\mathrm{O}$ cultivo de eucalipto apresenta perda da produtividade biológica presente nos ecossistemas induzindo a desertificação. Três fatores são importantes para essa indagação, a primeira é a demanda extrema de água que sucumbe a umidade do solo, assim como a recarga dos aquíferos subterrâneos. O segundo esta interligado a ciclo de nutrientes, pois esse cultivo demanda excessivo consumo, consequentemente criando deficiência desestabilizando o ciclo. O terceiro trata da redução da fertilidade do solo, levando em consideração "a liberação de substâncias químicas alopáticas afeta o crescimento de plantas e de microorganismos do solo" (Coelho-Neto e Avelar, 2007, p.73).

Nas Áreas de Vegetação Natural na bacia hidrográfica foi considerada apenas a cobertura Florestal, levando em consideração as matas nativas examinadas na área de estudo. As áreas que correspondem a Águas, são estritamente referentes as Águas Continentais, visto a utilização de áreas de banhado para construção de açudes, e a identificação de massa d'água a jusante devido a criação de Usina Hidrelétrica Dona Francisca no rio Jacuí.

O nível que contempla Outras Áreas, corresponde a Área Descoberta, refere-se aos solos expostos, que por estarem em exposição continua às chuvas, ocasionam o aumento no escoamento na superfície nas encostas em direção ao talvegue; assim, essas áreas são as com maior tendência a erosão superficial (Coelho-Neto e Avelar, 2007).

\section{Resultados e discussão}

\section{Unidades Geomorfométricas}

Conforme observa-se na Figura 2, as áreas com maiores altitudes localizam-se principalmente a montante da bacia e nas porções que correspondem aos morros e morrotes isolados. Essas áreas estão sujeitas aos processos de denudação e configuram $50,09 \%$ do total da área de estudo.

Por sua vez, as áreas com menores altitudes ocupam a porção que corresponde ao médio e ao baixo curso, representando $49,91 \%$ do total da bacia. É importante salientar que essas áreas representam a distinção de dois patamares: o primeiro com as altitudes maiores que correspondem a Unidade Geomorfológica dos Planaltos Gerais; e um segundo patamar que corresponde ao médio e ao baixo curso, sendo que até o médio curso ele corresponde a uma zona de transição entre as Unidade Geomorfológica dos Planaltos Gerais e Serra Geral e no baixo curso ele já representa a Serra Geral.

Com relação às declividades, predominam as superiores à $15 \%$ correspondendo à $51,21 \%$ da área da bacia, estendendo-se predominantemente no baixo e médio curso. As declividades inferiores a $15 \%$ somam $48,28 \%$ do total da área de estudo.

O plano de curvatura apresenta uma configuração onde as vertentes divergentes são as que predominam compondo $50,22 \%$ da área total da bacia, e as convergentes representando $49,79 \%$, distribuindo-se regularmente por toda a bacia hidrográfica.

O cruzamento dos parâmetros definidos gerou oito unidades distintas que podem ser observadas a partir das Figuras 2 e 3, a porcentagem da representação das unidades geomorfométricas podem ser verificadas na Figura 4.

As unidades geomorfométricas (UGs) I, II, III e IV (Figura 2) ocorrem nas maiores altitudes da bacia. As unidades I (amarelo claro) representa $16,35 \%$ e a II (verde claro) com 15,16\%, constituem as áreas menos inclinadas das encostas, onde a primeira forma as porções de topos compreendendo formas divergentes, e a segunda os canais e áreas de banhado por serem formas convergentes, em um relevo de colinas onduladas localizadas próximas ao interflúvio. 


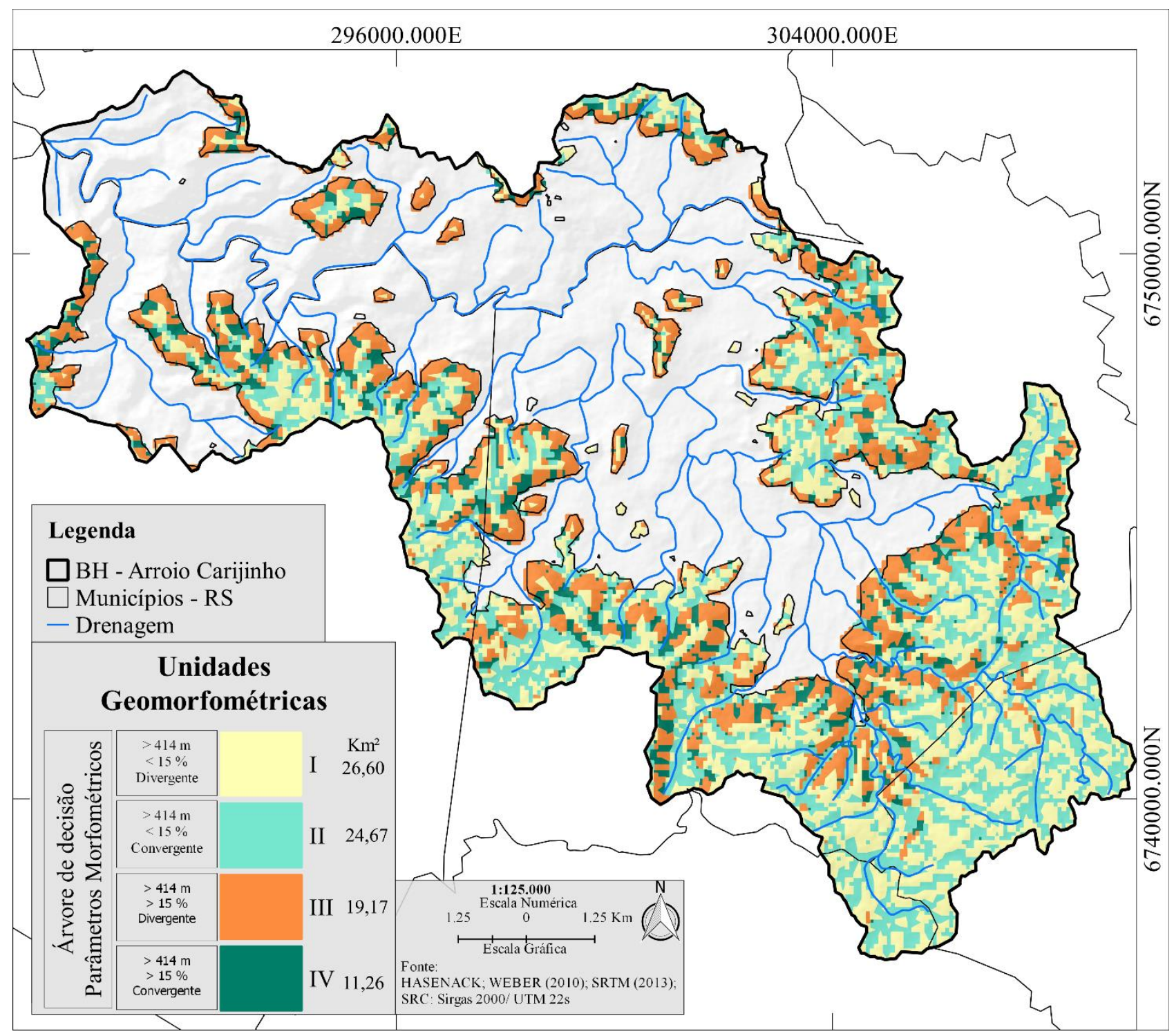

Figura 2 - Localização das unidades geomorfométricas com altitudes superiores a média.

A unidade III (laranja) apresenta área de $11,78 \%$ e a IV (azul petróleo escuro), possui percentual de $6,92 \%$. Essas áreas por apresentarem declividade elevada constituem as encostas de morros sendo a primeira as porções divergentes que apresenta tendência expressiva aos processos erosivos; e a segunda trata de áreas encaixadas da encosta com fluxo convergente. Essa área configura uma zona de transição entre dois patamares de colinas onduladas, e encontram-se em diversos segmentos da bacia (Figura 2).

As UGs V, VI, VII e VIII (Figura 3) representam as áreas com menores altitudes. A unidade V (laranja claro) representa 12,68\% correspondendo as áreas planas com formas divergentes. A unidade VI (verde) com 16,58\%, representa as áreas convergentes que representa o maior percentual entre todas unidades da bacia. Por suas características identifica-se que a partir dessa forma quando próxima ao canal representa áreas de planície com atuação de deposição sedimentar.

Esse segmento representado pelas UGs V e VII é considerada o segundo patamar por possuir características semelhantes as UGs I e II, porém separados por faixas de transição, cujo processo está ligado ao derrame vulcânico. Portanto, configura o segundo patamar e se concentra principalmente no médio curso, formando algumas planícies ao longo do canal. 


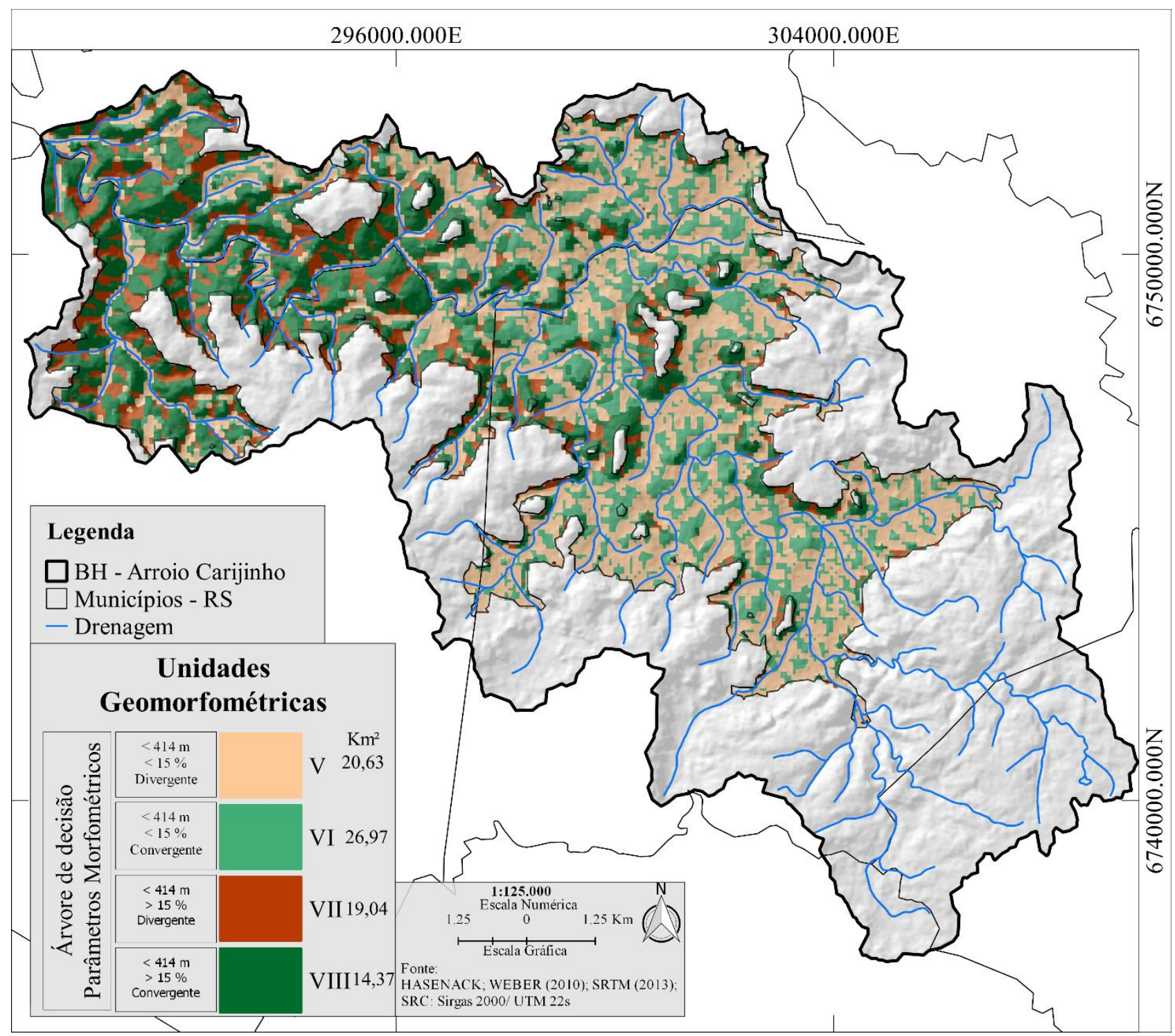

Figura 3 - Localização das unidades geomorfométricas com altitudes inferiores a média.

As UGs VIII (marrom) correspondem a $11,70 \%$ com declividade acentuada com formas divergentes e VII (verde escuro) tem as áreas convergentes e de declividade elevada correspondendo a $8,83 \%$ da bacia.

Essas unidades encontram-se no baixo curso, onde se observa uma drenagem encaixada em lineamentos estruturais. Também são identificáveis nas encostas dos morros e morrotes e nas áreas de transição.

Em relação a representação cartográfica das UGs, a palheta de cores utilizadas procura evidenciar com maior nitidez cada unidade.
A figura 4 apresenta nas áreas planas de altas altitudes as formas divergentes somam maior percentual com características de dispersão do fluxo. Nas baixas altitudes tem-se expressiva porcentagem das áreas com declividade baixa com formas convergente, assim representando concentração e acúmulo do escoamento. Já nas áreas com alta declividade representa formas divergentes que possui tendência a processos erosivos. 
Revista Brasileira de Geografia Física v11, n.03 (2018) 1112-1126.

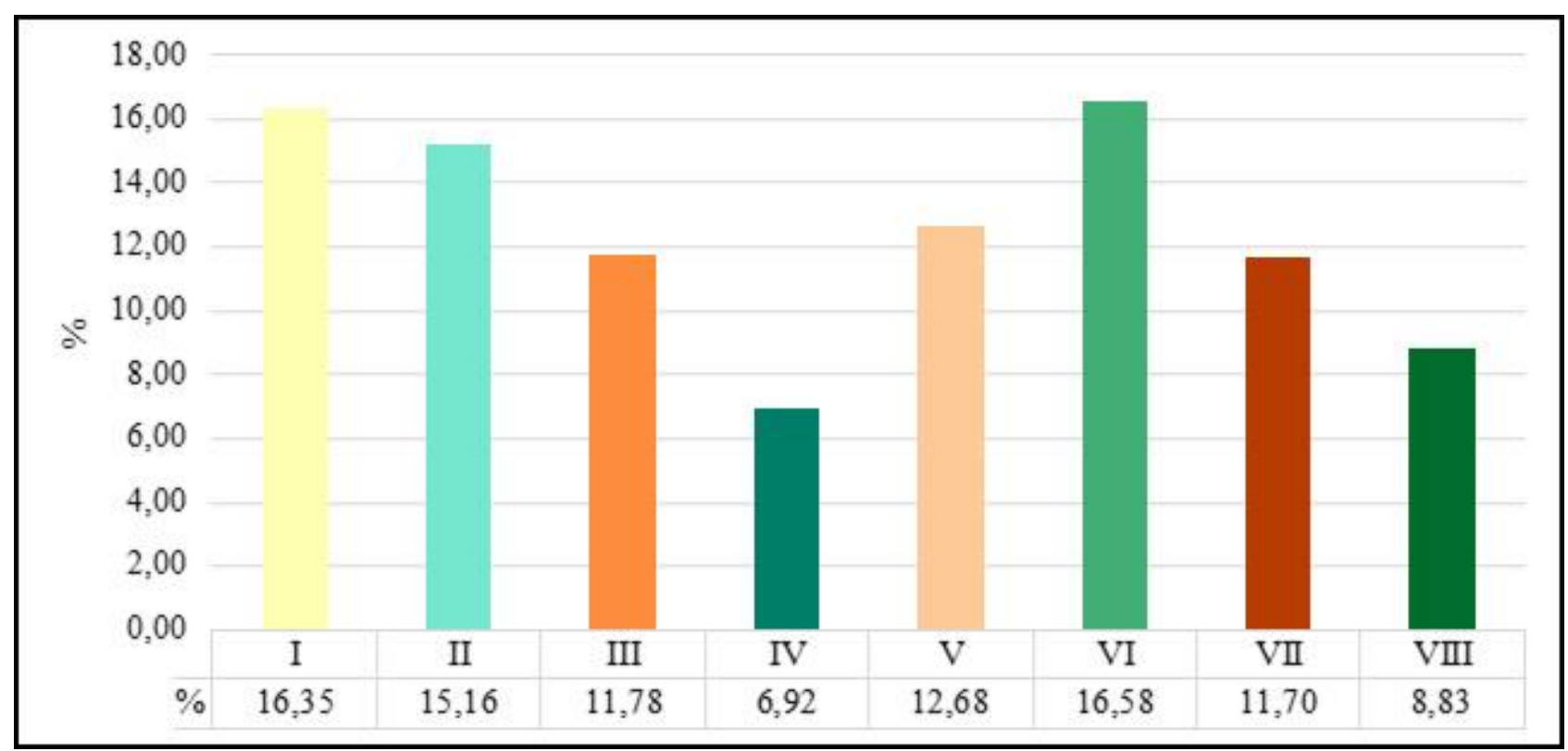

Figura 4: Gráfico representando a porcentagem de cada unidade geomorfométrica na bacia hidrográfica

\section{Cobertura e Uso da Terra}

Para indicar os tipos de cobertura e uso da terra, procurou-se evidenciar os dois níveis exemplificado pelo IBGE (2008), representados espacialmente na Figura 5 e em porcentagem de área ocupada na Figura 6.

As Áreas Antrópicas não Agrícolas correspondente a Área Urbana em rosa claro, concentram-se em duas áreas, a primeira localizase no município de Passa Sete, em que se assenta próximo as cabeceiras de drenagem e sobre o interflúvio da bacia e a segunda área com maior abrangência compreende o sítio urbano do município de Sobradinho. Dessa forma essas duas áreas urbanas não possuem saneamento básico, considerando que o esgoto produzido que não destina-se a fossa séptica é endereçado para os canais fluviais. Essa classe representa $1,09 \%$ da área da bacia hidrográfica.

As Áreas Antrópicas Agrícolas correspondem ao maior percentual de cobertura e uso da terra representando $54,31 \%$, e compreende a classe de Cultura Temporária representando as porções em ouro na Figura 5, correspondem 39,51 $\%$ e espacializam-se por todas as áreas da bacia. As áreas que correspondem a Pastagem em tom laranja representam 10,66 \%, as áreas de Silvicultura em laranja claro contemplam $4,13 \%$. 


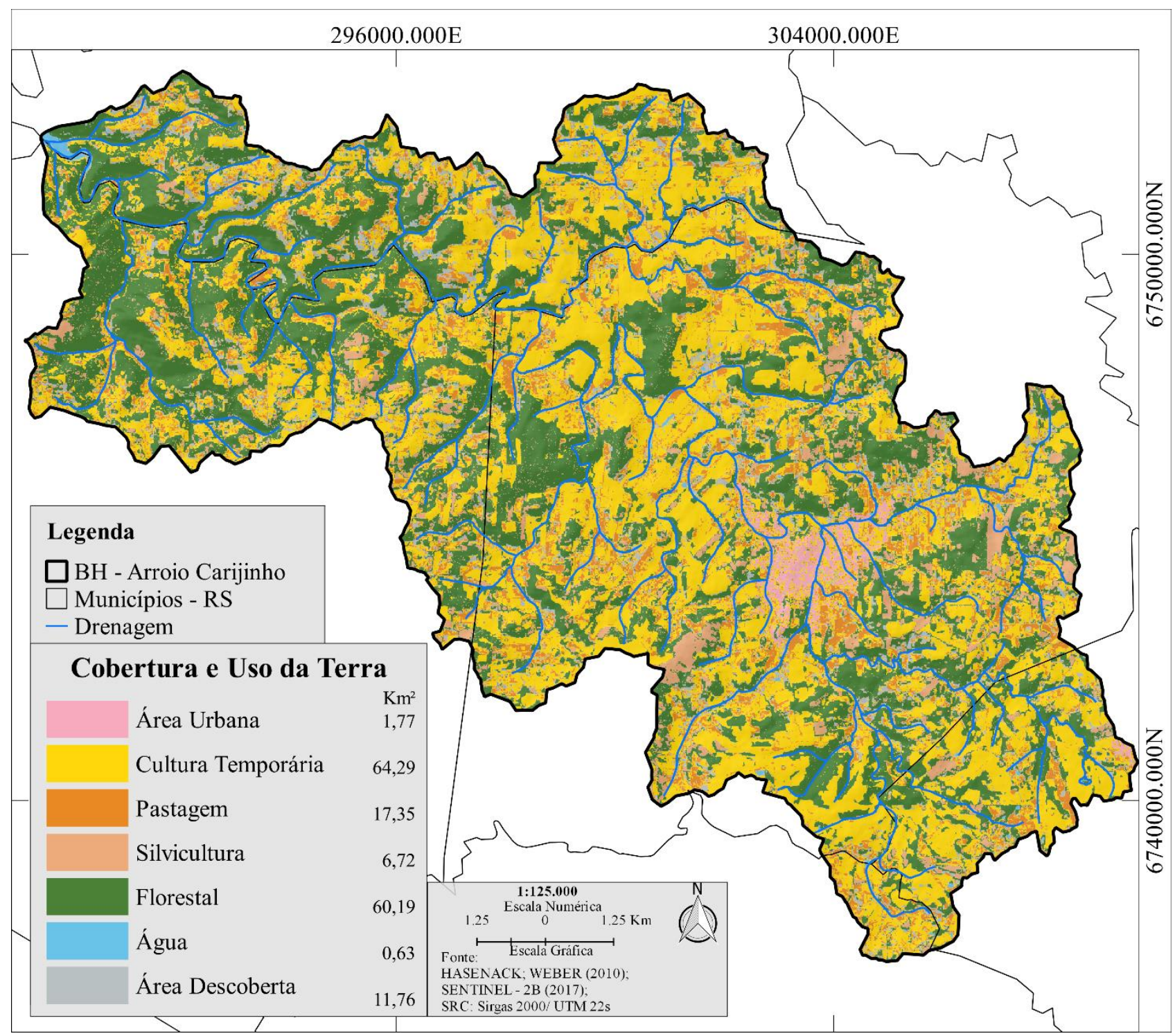

Figura 5: Cobertura e uso da terra bacia hidrográfica do Arroio Carijinho

As Áreas de Vegetação Natural, identificadas como Florestal em verde escuro representa $36,99 \%$ da área e se estendendo em diversos setores da bacia hidrográfica. As áreas com Águas continentais, expressa pelo tom verde água representam a menor porção da bacia, apenas $0,39 \%$.
As Outras Áreas, correspondendo as Área Descoberta em tom de cinza, representam solo exposto e áreas com superfície exposta, a exemplo dos paredões com formação basáltica e ainda áreas impermeabilizadas não urbanas, correspondem $7,23 \%$. 
Revista Brasileira de Geografia Física v11, n.03 (2018) 1112-1126.

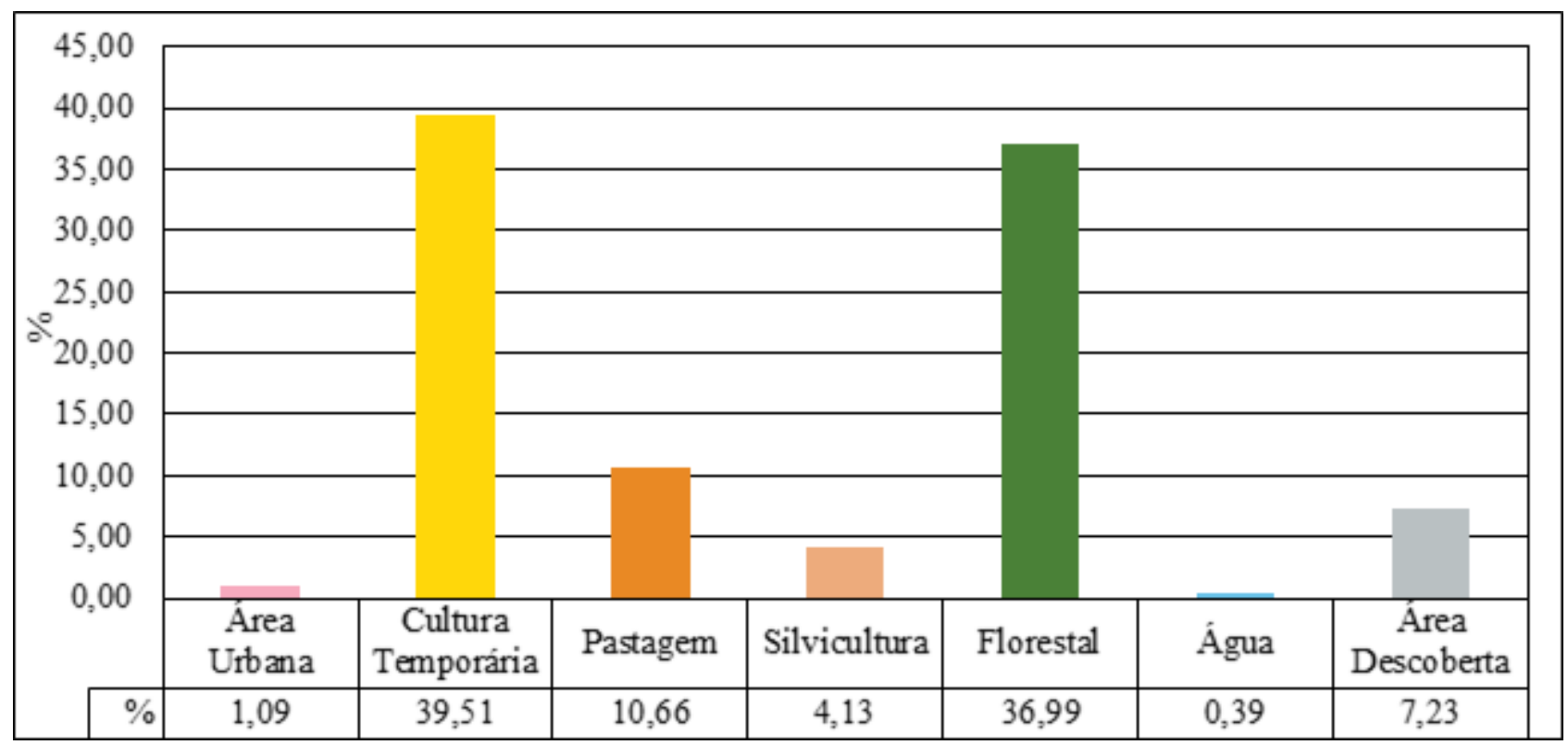

Figura 6: Gráfico - Porcentagem da Cobertura e Uso da Terra nas Unidades Geomorfométricas na bacia hidrográfica do Arroio Carijinho

\section{Cruzamento entre Unidades Geomorfométricas e Cobertura e Uso da Terra \\ O cruzamento entre a geomorfometria e as} classes de cobertura e uso da terra demonstram o comportamento das relações sociais desempenhada pelo ser humano sobre as Unidades Geomorfométricas do relevo. Essa relação pode ser apreciada em porcentagem a partir da Figura 7 e em área em $\mathrm{km}^{2}$ no Quadro 1.

Identifica-se que a classe Área Urbana concentra-se nas UGs V e VI apresentando aproximadamente $90 \%$ dessa classe nessas unidades. Nessa área está localizado o sítio urbano do município de Sobradinho, isso devido a proximidade do arroio como fonte de água e das ondulações do relevo que tornam-se em grande parte propícios à ocupação. Outra área com essa classe de cobertura, compõe a área urbana de Passa Sete, que encontra-se sobre o divisor de água e relaciona-se as UGs I e II. Em pequena porcentagem ocorre as UGs VII e VIII, essas áreas encontram-se no início da encosta do sítio urbano do município de Sobradinho.

As áreas que predominam Cultura Temporária concentram-se nas UGs planas tendo maior concentração percentual nas unidades I, VI, $\mathrm{V}$, II. Porém mesmo em áreas em que ocorrem processos erosivos identifica-se a presença dessas coberturas, o que faz intensificar de maneira significativa a perda de matéria orgânica e acelerar o processo de decomposição do material rochoso basáltico resultando no assoreamento dos canais fluviais. Verifica-se que nas formas divergentes de alta declividade (III e VII) possuem maior proporção que as demais com mesma declividade (IV e VIII). 


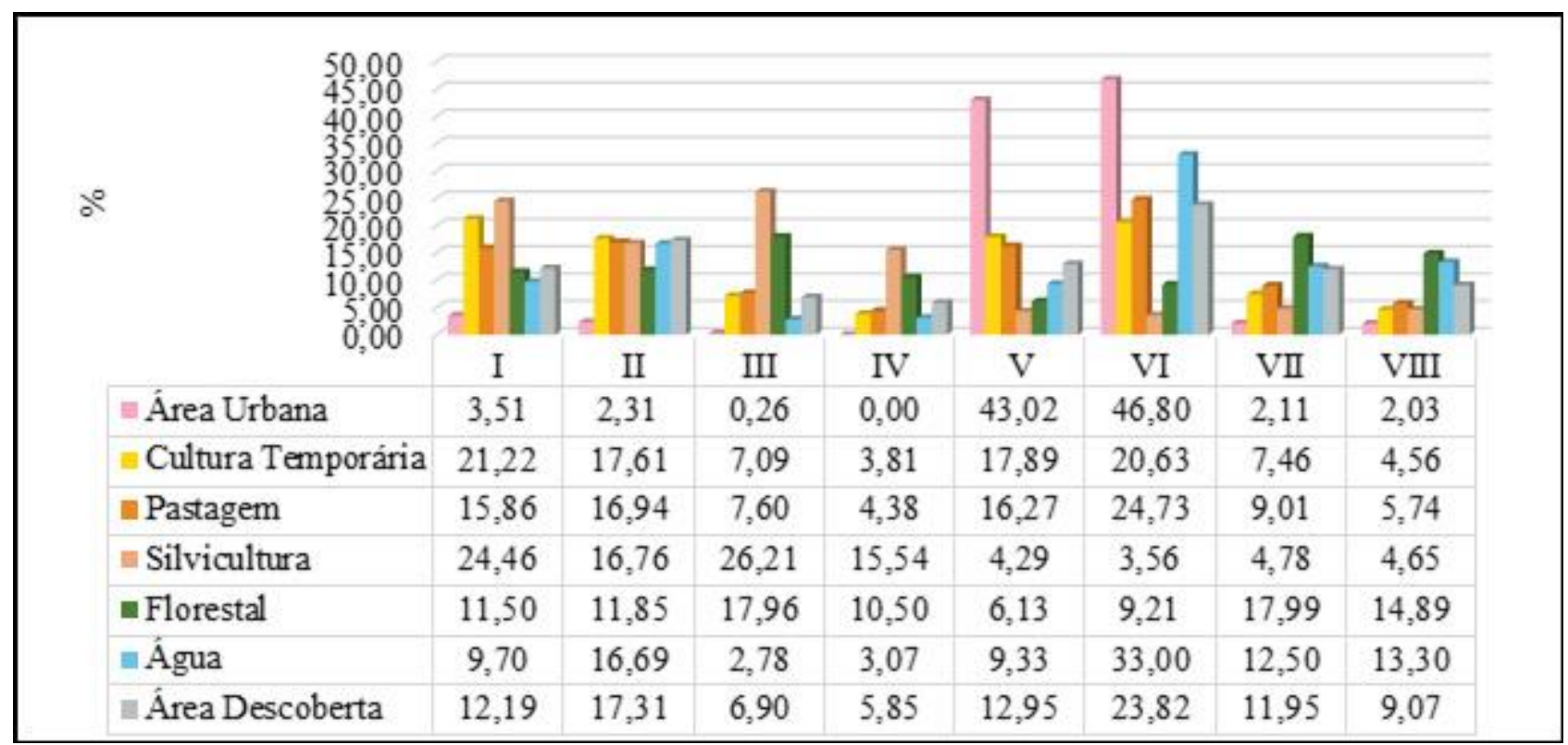

Figura 7: Gráfico - Porcentagem cruzamento entre Cobertura e Uso da Terra e Unidades Geomorfométricas

As pastagens estão presentes em todas unidades, onde com maior proporção encontra-se a UG VI, em sequência tem-se a UG II, portanto, correspondem as formas convergentes das áreas planas. Outra unidade com porcentagem significativa de pastagens encontra-se na UG I.

A silvicultura apresenta-se principalmente nas unidades que encontram-se na UG V, porém também apresenta-se concentração dessa classe de cobertura nas UGs III e I. Compreende-se então que as três maiores proporções dessa cultura encontram-se sobre formas divergentes. Com a implementação massiva dessa cultura, muitas áreas de mata nativa foram suprimidas para o cultivo da silvicultura.

A cobertura classificada como floresta são perceptíveis em todas as UGs, porém devido a inclinação das vertentes aglomeram-se nas UGs III e VIII por serem formas divergentes e com declividade acima de $15 \%$. As UGs I e II possuem quase o mesmo percentual dessa cobertura, apresentando que mesmo em uma pequena porção ainda encontra-se algumas áreas de floresta próximo as cabeceiras e canais de drenagem fluvial. Em menor proporção correspondente a essa classe encontram-se UGs V e VI.

A classe equivalente a água concentra-se na UG VI, em sequência representa grande porcentagem na UG VII, portanto mais de $50 \%$ da área que contem água estão na parte inferior da bacia hidrográfica. Na parte superior da bacia possuem quase mesma porcentagem as UGs I e II. As UGs III e IV são as áreas com menor presença de água devido sua inclinação. Também se tem grande concentração de água próximo ao final do baixo curso devido a Usina Hidrelétrica Dona Francisca que represa o Rio Jacuí, consequentemente o Jacuizinho e seu contribuinte o Carijinho.

A cobertura composta por áreas descobertas é identificável em todas unidades geomorfométricas, porém quando estão associadas as altas declividades podem exercer grande potencial erosivo. $\mathrm{Na}$ parte superior da bacia apresenta-se principalmente na unidade II que por ser convergente e de baixa declividade induz que trata-se de áreas em preparo para novos loteamentos ou utilização para extração de material basáltico. $\mathrm{Na}$ parte inferior verifica-se grande presença dessa classe principalmente em formas convergentes em que aumenta a concentração e acumulo de escoamento acelerando o processo de carreamento dos sedimentos para o canal fluvial. Também pode ser associado as rochas basálticas desnudas próximas ao baixo curso. 
Revista Brasileira de Geografia Física v11, n.03 (2018) 1112-1126.

\begin{tabular}{|c|c|c|c|c|c|c|c|c|c|}
\hline \multicolumn{2}{|c|}{ Unidades Geomorfométricas } & I & II & III & IV & $\mathrm{V}$ & VI & VII & VIII \\
\hline \multirow{7}{*}{ 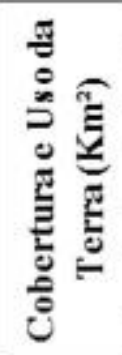 } & Área Urbana & 0,06 & 0,04 & 0,00 & 0,00 & 0,76 & 0,83 & 0,04 & 0,04 \\
\hline & Cultura Temporária & 13,64 & 11,32 & 4,56 & 2,45 & 11,50 & 13,26 & 4,80 & 2,93 \\
\hline & Pastagem & 2,75 & 2,94 & 1,32 & 0,76 & 2,82 & 4,29 & 1,56 & 1,00 \\
\hline & Silvicultura & 1,64 & 1,13 & 1,76 & 1,04 & 0,29 & 0,24 & 0,32 & 0,31 \\
\hline & \begin{tabular}{|l|} 
Florestal \\
\end{tabular} & 6,92 & 7,13 & 10,81 & 6,32 & 3,69 & 5,55 & 10,83 & 8,96 \\
\hline & Água & 0,06 & 0,11 & 0,02 & 0,02 & 0,06 & 0,21 & 0,08 & 0,08 \\
\hline & Area Descoberta & 1,43 & 2,04 & 0,81 & 0,69 & 1,52 & 2,80 & 1,41 & 1,07 \\
\hline
\end{tabular}

Quadro 1: Cruzamento entre Cobertura e Uso da Terra e Unidades Geomorfométricas

O comportamento dessas UGs tanto sob a ótica das unidades geomorfométricas quanto da textura representado pela cobertura e uso da terra podem ser visualizados seu comportamento in loco a partir das Figuras 8, 9, 10 e 11. Na figura 5, predomina o plantio de soja nessa porção da bacia que encontra-se no alto curso próximo as principais nascentes do Arroio Carijinho e representa as unidades I e II consideradas como colinas onduladas.

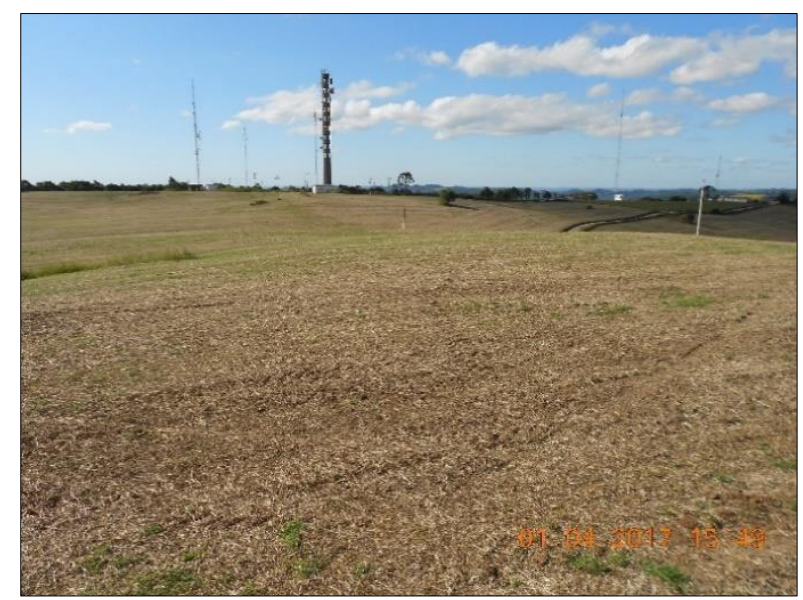

Figura 8 - Representação das unidades I e II

A Figura 9 apresenta vertentes divergentes e convergentes apresentando as unidades III e IV (área de transição) compondo uma área representada por uma associação entre morros e morrotes, nessas áreas existe o predomínio de mata nativa devido a forte inclinação.

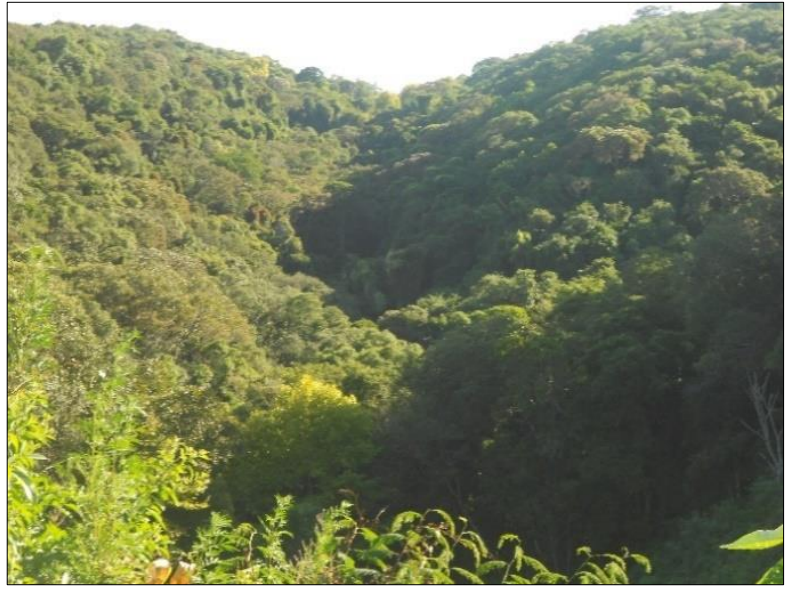

Figura 9 - Representação das unidades III e IV

A figura 10 apresenta uma área plana representando as unidades V e VI (médio curso), nela é identificável pequenas porções de capões de mato próximo ao canal fluvial do Arroio Bonito. Verifica-se segmentos de culturas temporárias e pastagens, essa porção representa formas de colinas onduladas.

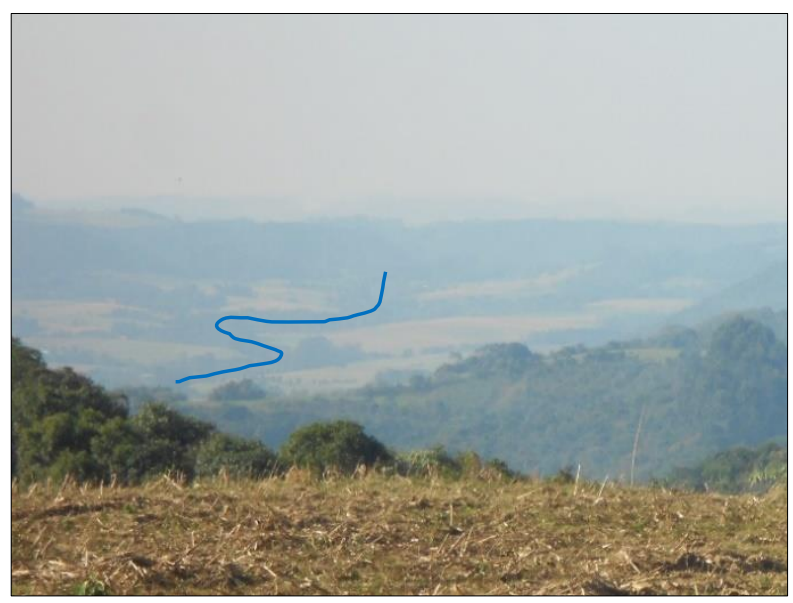

Figura 10 - Representação das unidades V e VI

A figura 11 representa o baixo curso da bacia hidrográfica, que no segundo plano da fotografia corresponde as unidades VII e VIII que associam-se ao rebordo da serra geral, nela são 
observáveis área de mata nativa e pastagens por se tratar de uma área com inclinações elevadas.

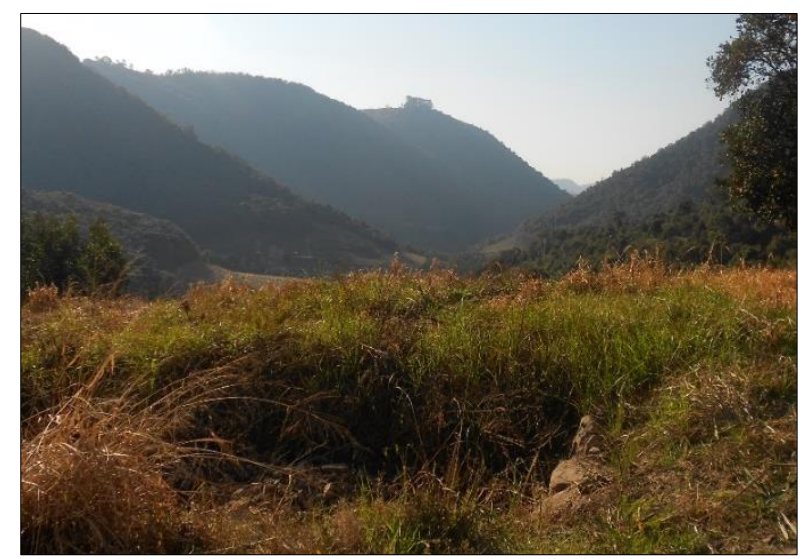

Figura 11 - Representação das unidades V e VI

A partir do exposto fica claro o predomínio de Área Urbana no município de Sobradinho nas UGs V e VI que próximo ao canal podem oferecer contaminação do canal fluvial. Também apresentam porcentagem na UGs VII e VIII que apresentam preocupação devido a inclinação das encostas. Outra composição dessa classe encontrase nas UGs I e II que estão no município de Passa Sete.

As Culturas Temporárias aplicadas nas UGs II e VI de forma convergente próximo ao canal fluvial, pode tornar um problema, isso devido a utilização de maquinário agrícola que auxilia na descompactação do solo e acelera os processos erosivos e seu transporte para o canal. A utilização de agrotóxicos muito utilizado no plantio de fumo de estufa, soja e trigo também torna-se um problema, pois a cada chuva esse conteúdo e transportado para os canais fluviais. A aplicação dessa cobertura nas UGs acima de 15\% (III, IV, VII e VIII) também se torna um problema devido a ocorrência de processos erosivos em razão da descompactação do solo utilizando arado tração animal.

Verifica-se a presença de Silvicultura na parte alta da bacia, isso trona-se preocupante em relação que nas UG II que se encontram os canais e as nascentes, assim como nas UGs III e IV podem acelerar o fluxo da água e por consequência desenvolver processos erosivos.

As áreas descobertas também trazem preocupações principalmente nas UGs acima de 15\% (III, IV, VII e VIII), pois devido a inclinação podem acelerar o fluxo de água carreando os sedimentos descobertos.

\section{Considerações finais}

$\mathrm{O}$ presente estudo objetivou realizar a compartimentação do relevo da bacia hidrográfica do Arroio Carijinho a partir da utilização dos parâmetros altitude, declividade e plano de curvatura, definindo assim oito unidades geomorfométricas para a área de estudo.

É importante destacar que a realização dos trabalhos de campo, pois esses tiveram como objetivo a conferência in loco dos produtos cartográficos gerados a partir do geoprocessamento dos dados coletados. O levantamento fotográfico auxiliou a conferência do modelo gerado frente a realidade, para uma melhor caracterização da área de estudo. A prática do trabalho de campo possui caráter didático-pedagógico e é instrumento de análise que ajuda na análise e interpretação da realidade da área de estudo.

Ressalta-se a necessidade de utilização das ferramentas disponibilizadas nos SIGs, assim como o Geoprocessamento utilizado para gerar o mapeamento das unidades geomorfométricas a partir de modelos digitais do terreno. Assim como a utilização do Sensoriamento Remoto para identificação das diferentes coberturas e uso da terra.

Por fim, evidencia importância do relevo e da geomorfologia no planejamento ambiental aliado ao ordenamento territorial, tendo como base a definição de locais apropriados para os diferentes usos. Sendo assim, é importante buscar alternativas que tenham como objetivo identificar diferentes elementos em suas dimensões naturais e antrópicas a partir da caracterização do relevo. Portanto fica evidente a importância das geotecnologias na aplicação de mapeamentos do relevo.

\section{Agradecimentos}

A Coordenação de Aperfeiçoamento de Pessoal de Nível Superior (CAPES) pela concessão da bolsa de estudos dos primeiros autores.

\section{Referências}

Araujo, G.H. de S., Almeida, J.R. de., Guerra, A.J.T., 2010. O papel da geomorfologia no diagnóstico de áreas degradadas, in:__ (Org.), Gestão Ambiental de áreas degradadas. Bertrand Brasil, Rio de Janeiro, pp. 53-61.

Bispo, P.C., Valeriano, M.M., Kuplich, T.M., 2009. Variáveis geomorfométricas locais e sua relação com a vegetação da região do interflúvio Madeira-Purus (AM-RO). Acta Amazônica 39, 81-90.

Botelho, R.G.M., Silva, A.S da., 2010. Bacia hidrográfica e qualidade ambiental, in: Vitte, 
A.C., Guerra, A. J.T. (Org.), Reflexões sobre a geografia física no Brasil. 3 ed. Bertrand Brasil, Rio de Janeiro, pp. 153-192.

Botelho, R.G.M., 2011. Bacias hidrográficas urbanas, in: Guerra, A.J.T. (Org.), Geomorfologia urbana. Bertrand Brasil, Rio de Janeiro, pp. 71-115.

Chagas, C.S., 2006. Mapeamento digital de solos por correlação ambiental e redes neurais em uma bacia hidrográfica no domínio de mar de morros. Tese (Doutorado), Viçosa, Universidade Federal de Viçosa.

Coelho Netto, A.L., Avelar, A. de. S., 2007. O uso da terra e a dinâmica hidrológica comportamento hidrológico e erosivo de bacias de drenagem, in: Santos, R.F. dos. (Org.), Vulnerabilidade ambiental: Desastres naturais ou fenômenos induzidos? Ministério do Meio Ambiente, Brasília, pp. 65-73.

CBH. Comitê de Bacias Hidrográficas, 2017. Informações. http://www.cbh.gov.br/

GestaoComites.aspx\#not-interestaduais.

Acesso: 31 jul. 2017.

Dias, D. F., Trentin, R., Marques, R.D., 2016. Utilização de parâmetros geomorfométricos para a classificação do relevo do município de Mata - RS. Revista GEOgrafias [online] 12. Disponível:

http://www.igc.ufmg.br/portaldeperiodicos/ind ex.php/geografias/article/view/778/572. Acesso: 30 set. 2017.

ESRI. Environmental Systems Research Institute, 2017. License Manager and Installation. Disponível: http://desktop.arcgis.com/en/ desktop/ latest/get-started/license-managerguide/license-manager-installation-andstartup.htm/. Acesso: 10 mar. 2016.

ESRI. Environmental Systems Research Institute. Curvature (Spatial Analyst). Disponível: http://resources.arcgis.com/en/help/main/10.1/i ndex.html\#//009z000000tw000000. Acesso: 05 dez. 2017.

ESRI. Environmental Systems Research Institute, 2017. Fill (Spatial Analyst). Disponível: http://resources.arcgis.com/ en/help/main/10.1/index.html\#//009z00000050 000000. Acesso: 05 dez. 2017.

Fitz, P.R., 2008. Cartografia básica. Oficina de textos, São Paulo.

Florenzano, T.G., 2008. Introdução à Geomorfologia, in:_ (Org.), Geomorfologia: conceitos e tecnologias atuais. Oficina de Textos, São Paulo, pp. 11 - 30.

Guadagnin, P.M.A., Trentin, R., 2014. Compartimentação geomorfométrica da bacia hidrográfica do Arroio Caverá - RS. Geo UERJ [online] 16. Disponível: http://www.epublicacoes.uerj.br/index.php/geouerj/article/vi ew/10030/9928. Acesso: 14 set.2017.

Guadagnin, P.M.A., Trentin, R., Alves, F.S., 2015. Relação entre as Variáveis Geomorfométricas e a Vegetação Florestal na Bacia Hidrográfica do Arroio Caverá-Oeste do RS. Revista do Departamento de Geografia [online] 29. Disponível:

http://www.revistas.usp.br/rdg/article/view/102 131/100552. Acesso: 14 set. 2017.

Guerra, A.T., Guerra, A.J.T., 1997. Novo dicionário-geológico-geomorfológico, Bertrand Brasil, Rio de Janeiro.

Hasenack, H., Weber, E., 2010. Base Cartográfica Vetorial Contínua do Rio Grande do Sul. UFRGS, Porto Alegre.

IBGE. Instituto Brasileiro de Geografia e Estatística, 2003. Mapeamento Geomorfológico, 1:250.000 Carta Santa Maria SH. 22 - V - C. Rio de Janeiro.

IBGE. Instituto Brasileiro de Geografia e Estatística, 2013. Manual Técnico de Uso da Terra. 3 ed. Rio de Janeiro.

IPT. Instituto de Pesquisas Tecnológicas, 1981. Mapeamento Geomorfológico do Estado de São Paulo. São Paulo.

Ippoliti, G.A., Costa, L.M., Schaefer, C.E.G. R., Fernandes Filho, E.I., Gaggero, M.R., Souza, E., 2005. Análise digital do terreno: ferramenta na identificação de pedoformas em microbacia na região de "Mar de Morros" (MG). Revista Brasileira de Ciência do Solo 29, 269-276.

Martinoni, D., 2002. Models and experiments for quality handling in digital terrain modelling. Thesis (Ph.D). Zürich, University of Zürich.

Moore, I. D.; Gessler, G.A.; Peterson, G.A., 1993 Soil attribute prediction using terrain analysis. Soil Science Society of America Journal 57, 443-452.

Moore, I.D., Grayson, R.B., Ladson, A.R., 1991. Digital terrain modeling: a review of hydrological, geomorphological, and biological applications. Hydrological Processes 5, 3-30.

Muñoz, V.A., 2009. Análise geomorfométrica de dados SRTM aplicada ao estudo das relações solo-relevo. Dissertação (Mestrado), São José dos Campos, INPE.

Pennock, D.J., 2003. Terrain attributes, landform segmentation, and soil redistribution. Soil and Tillage Research 69, 15-26.

Prina, B.Z., Trentin, R., 2016. Caracterização detalhada das unidades de relevo do município de Jaguari (RS)/Brasil. Caderno de Geografia 26, 404-426. 
Trentin, R., Robaina, L.E.S., 2016. Classificação das unidades de relevo através de parâmetros geomorfométricos. Mercator 15, 53-66.

Schmidt, J., Dikau, R., 1999. Extracting geomorphometric attributes and objects from digital elevation models semantics, methods, future needs, in: Dikau, R., Saurer, H. (Org.), GIS for Earth Surface Systems Analysis and Modelling of the Natural Environment. Gebruder Borntraeger, Berlin, pp. 153-173.

Shary, P.A., Sharaya, L.S., Mitusov, A.V., 2002. Fundamental quantitative methods of land surface analysis. Geoderma 107, 1-32.

Silva, A.S da., 2010. Solos urbanos, in: Guerra, A.J.T. (Org.), Geomorfologia urbana. Bertrand Brasil, Rio de Janeiro, pp. 43-69.

Silveira, C.T., Oka-Fiori, C., Santos, L.J.C., Sirtoli, A.E., Silva, C.R., 2012. Pedometria apoiada em atributos topográficos com operações de tabulação cruzada por álgebra de mapas. Revista Brasileira de Geomorfologia 13, 125134.

Silveira, C.T., Fiori, A.P., Ferreira, A.M., Góis, J.R., Mio, G., Silveira, R.M.P., Massulini, N.E.B., Leonardi, T.M.H., 2013. Emprego de atributos topográficos no mapeamento da susceptibilidade a processos geoambientais na bacia do Rio Jacareí/Paraná. Sociedade \& Natureza 25, 623-639.

Sirtoli, A. E. et al., 2008. Parâmetros do relevo derivados do modelo digital de elevação e suas relações com solos. Scientia Agraria 9, 317-329.

Speight, J.G., 1968. Parametric description of landform, in: Stewart, G.A. (Org.), Land evaluation. Macmillan, Austrália, pp. 239-250.

Trentin, R., Robaina, L.E.S., Silveira, C.T., 2015. Compartimentação Geomorfométrica da Bacia Hidrográfica do Rio Itú/RS. Revista Brasileira de Geomorfologia [online] 2. Disponível: http://www.lsie.unb.br/rbg/index.php/rbg/articl e/view/460/459. Acesso: 10 fev. 2018.
USGS. United States Geological Survey, 2012. Shuttle Radar Topography Mission. 3-ARC. Disponível: http://srtm.usgs.gov/. Acesso: 09 jan. 2016.

Valeriano, M.M., 2005. Modelo digital de variáveis morfométricas com dados SRTM para o território nacional: o projeto Topodata, in: XII Simpósio Brasileiro de Sensoriamento Remoto, Goiânia, Anais... pp. 1-8.

Valeriano, M.M., 2003. Curvatura vertical de vertentes em microbacias pela análise de modelos digitais de elevação. Revista Brasileira de Engenharia Agrícola e Ambiental 7, 539546.

Valeriano, M.M., Carvalho Junior, O.A., 2003. Geoprocessamento de modelos digitais de elevação para mapeamento da curvatura horizontal em microbacias. Revista Brasileira de Geomorfologia [online] 4. Disponível: http://www.lsie.unb.br/rbg/index.php/rbg/articl e/view/17/15. Acesso: 20 set. 2017.

Vasconcelos, V., Carvalho Júnior, O.A., Martins, E.S.; Couto Junior, A.F., Guimarães, R.F., Gomes, R.A.T., 2012. Sistema de classificação geomorfométrica baseado em uma arquitetura sequencial em duas etapas: árvore de decisão e classificador espectral, no Parque Nacional Serra da Canastra. Revista Brasileira de Geomorfologia [online] 13. Disponível: http://www.lsie.unb.br/rbg/index.php/rbg/articl e/view/248/293. Acesso: 09 nov. 2017.

Wilson, J.P., Gallant, J.C., 2000. Terrain analysis: principles and applications, John Wiley \& Sons, New York.

Wood, J., 1996. The geomorphological characterisation of digital elevation models. Thesis (PhD), Leicester, University of Leicester. 